\title{
'Know Your Epidemic': Are Prisons a Potential Barrier to TB Elimination in an Australian Context?
}

\author{
Nompilo Moyo ${ }^{1, *(\mathbb{D})}$, Ee Laine Tay ${ }^{2}$ and Justin Denholm ${ }^{1,3}$ (ii) \\ 1 The Victorian Tuberculosis Program at the Peter Doherty Institute, Melbourne, VIC 3000, Australia; \\ justin.denholm@mh.org.au \\ 2 Health Protection Branch, Department of Health and Human Services, Melbourne, VIC 3000, Australia; \\ EELaine.Tay@dhhs.vic.gov.au \\ 3 Department of Microbiology and Immunology, University of Melbourne, Melbourne, VIC 3000, Australia \\ * Correspondence: nompilo.moyo@mh.org.au; Tel.: +61-41-005-8750
}

Received: 12 August 2018; Accepted: 27 August 2018; Published: 31 August 2018

\begin{abstract}
Globally, rates of tuberculosis (TB) cases in prisons are substantially higher than in the general population. The goal of this study was to review TB notifications in Victorian correctional facilities, and consider whether additional interventions towards TB elimination may be useful in this setting. All patients who were notified with or treated for TB in the Australian state of Victoria from 1 January 2003 to 1 December 2017 were included in this study. Descriptive analysis was performed. Demographic and treatment outcome data for individuals with and without a history of incarceration were reviewed and compared. Of the 5645 TB cases notified during the study period, $26(0.5 \%)$ had a history of being incarcerated in correctional facilities while receiving treatment for TB. There were 73,238 inmates in Victorian correctional facilities over the same study period, meaning that approximately $0.04 \%$ of inmates were diagnosed or treated with TB disease in correctional facilities. Incarcerated individuals were more likely to have positive sputum smears and cavitation compared with nonincarcerated people with TB. There was no significant difference in treatment outcomes between the general TB population and those who had a history of incarceration during their treatment. There is a low apparent rate of TB in Victorian prisoners, and prisons do not contribute significantly to TB incidence in Victoria. Overall, TB outcomes do not differ between prisoners and nonprisoners. Ongoing efforts to sustain these lower rates and comparable outcomes in this vulnerable cohort are important for continued progress towards TB elimination.
\end{abstract}

Keywords: correctional facilities; tuberculosis; treatment; incarceration

\section{Introduction}

In many global contexts, prisons are recognised to be important sites for tuberculosis (TB) exposure, reactivation, and morbidity [1]. This phenomenon arises for a collection of reasons, including factors relating to prisoner characteristics (for example, smoking and malnutrition) and those which may arise from confinement (such as overcrowding and poor ventilation) [2,3]. Depending on health facilities available to prisoners, inadequate infection control or delays in diagnosis and treatment may further increase the risk of TB transmission and poor outcomes associated with disease [2,3].

Globally, rates of TB cases in correctional facilities are 26 times higher compared with the general population [4]. Although TB incidence rates among correctional populations in the United States have been shown to be steadily declining recently, incarcerated populations continue to experience TB at a substantially higher incidence than in the general population $[5,6]$.

Few studies have been previously conducted on TB in Australian correctional facilities, and have primarily focused on TB infection among current prison inmates $[7,8]$. To our knowledge, no studies 
have previously considered the contribution of incarceration to overall TB incidence. Effective progress towards TB elimination requires awareness of local risk groups and consideration of appropriately targeted strategies. We sought to describe the association between TB and incarceration in Victoria, Australia, in order to evaluate the need for prison-specific approaches to TB elimination.

\section{Materials and Methods}

Data on all cases of TB notified between 1 January 2003 and 31 December 2017 were extracted from the Department of Health and Human Services Public Health Events Surveillance System (PHESS), a centralised database containing demographic, clinical, risk factors, and contact tracing information, laboratory results, treatment details, and outcomes for all TB cases in Victoria. Medical practitioners and diagnostic laboratories are required under Victorian public health legislation to report cases of TB to health authorities [9], and all notified cases of TB are managed by the Victorian Tuberculosis Program. A microbiologically-confirmed case of TB requires culture or polymerase chain reaction (PCR) diagnosis of Mycobacterium tuberculosis, while clinical/radiological diagnosis may also be made by a medical practitioner experienced in TB management. Approximately $85 \%$ of TB cases in Victoria are culture-confirmed [10].

Case notes were searched for reference to incarceration, either as a clinician-identified risk factor, or through free text searches for the words 'prison', 'jail', 'correction', 'custody', 'justice', 'remand', 'magistrate', and for specific names of local prisons or forensic units. Case notes were reviewed and individuals with TB were eligible for inclusion in this study if they had been imprisoned in Victoria at any time, while those with a prior history of incarceration only outside of the state or overseas were excluded. Background demographic data on the general prison population was collected from the Australian Bureau of Statistics [11-25].

In Victoria, initial isolates of the M. tuberculosis complex, as well as repeat isolates from relapse cases or 'treatment failures', are tested for susceptibility to at least isoniazid, ethambutol, rifampicin, and pyrazinamide. Additional drugs are tested when resistance to first-line agents is found. The susceptibility tests are performed by Victorian Infectious Diseases Reference Laboratory [26].

\subsection{Data Analysis}

All data preparation and analysis was conducted using Stata version 14.0 (Stata Corp., College Station, TX, USA). Descriptive analysis was performed and comparisons in demographics, clinical characteristics, and treatment outcomes were made between cases in the general TB population and the cases that had their TB treatment in prison. Between-group comparisons were conducted with two-sided Fisher's exact test for categorical variables due to small sample size or Wilcoxon/Mann-Whitney tests for continuous variables, with $p$ values of $<0.05$ considered significant.

\subsection{Ethics Statement}

The data on PHESS were collected under the legislative authority of the Public Health and Wellbeing Act 2008, and therefore, approval from a Human Research Ethics Committee for this study was not required under the rules of our institutions.

\section{Results}

Of the 5645 TB cases notified between 1 January 2003 and 31 December 2017, the search strategy identified 116 potential cases for inclusion. Following case notes review, 26 cases $(0.5 \%)$ met the study criteria of being incarcerated in correctional facilities at the time they were diagnosed or in receipt of treatment for TB, and were included in this analysis. With 73,238 inmates in Victorian correctional facilities over the same study period [12-26], this represents $0.04 \%(26 / 73,238)$ of inmates who were diagnosed or treated with tuberculosis disease in correctional facilities.

The characteristics of these cases and the general TB population are presented in Table 1. Prisoners were more likely to be male and were younger than the general population with TB. 
While site of disease did not vary significantly, prisoners were also more likely to have relapsed following previous treatment $(15.4$ versus $2.7 \% ; p=0.018)$ and to have smear-positive disease (38.5 versus $30.2 \% ; p=0.047)$.

Table 1. Characteristics of participants.

\begin{tabular}{|c|c|c|c|c|c|}
\hline \multirow[t]{2}{*}{ Variables } & \multicolumn{2}{|c|}{ Prison } & \multicolumn{2}{|c|}{$\begin{array}{l}\text { General TB } \\
\text { Population }\end{array}$} & \multirow[t]{2}{*}{$p$ Value $^{3}$} \\
\hline & $n$ & $(\%)$ & $n$ & $(\%)$ & \\
\hline Total & 26 & & 5619 & & \\
\hline \multicolumn{6}{|l|}{ Gender } \\
\hline Male & 24 & (92.3) & 3058 & (54.4) & \\
\hline Female & 2 & $(7.7)$ & 2561 & $(45.6)$ & $<0.0001$ \\
\hline \multicolumn{6}{|l|}{ Age in years } \\
\hline$<30$ & 17 & $(65.4)$ & 2257 & $(40.2)$ & \\
\hline$\geq 30$ & 9 & $(34.6)$ & 3362 & $(59.8)$ & 0.008 \\
\hline Median age (IQR) & 26.5 & $(23-36)$ & 33 & $(25-53)$ & $0.0271^{4}$ \\
\hline \multicolumn{6}{|l|}{ Country of birth } \\
\hline Australian & 2 & $(7.7)$ & 573 & $(10.2)$ & \\
\hline Overseas & 24 & (92.3) & 5041 & $(89.7)$ & \\
\hline Not stated & 0 & $(0.0)$ & 5 & $(0.1)$ & 1.000 \\
\hline \multicolumn{6}{|l|}{ Site of disease } \\
\hline Pulmonary & 13 & (50) & 2353 & $(41.9)$ & \\
\hline Pulmonary plus other sites & 5 & $(19.2)$ & 759 & $(13.5)$ & \\
\hline Extrapulmonary & 8 & (30.8) & 2507 & $(44.6)$ & 0.315 \\
\hline Sputum smear positive ${ }^{1}$ & 10 & $(38.5)$ & 941 & $(30.2)$ & 0.047 \\
\hline Lung cavity on chest $\mathrm{X}$ ray $(\mathrm{CXR})$ or computed tomography $(\mathrm{CT})^{1}$ & 7 & $(38.9)$ & 606 & $(6.0)$ & 0.099 \\
\hline \multicolumn{6}{|l|}{ Drug susceptibility testing ${ }^{2}$} \\
\hline Fully susceptible & 19 & $(100)$ & 3958 & $(91.1)$ & \\
\hline MDR TB & 0 & $(0.0)$ & 80 & $(1.8)$ & \\
\hline Mono- or polyresistant (not MDR TB) & 0 & $(0.0)$ & 290 & (6.7) & \\
\hline Not tested or recorded & 0 & $(0.0)$ & 19 & $(0.4)$ & NC \\
\hline \multicolumn{6}{|l|}{ Treatment history } \\
\hline New case & 22 & $(84.6)$ & 5377 & (95.7) & \\
\hline Relapse following full treatment & 4 & $(15.4)$ & 150 & $(2.7)$ & \\
\hline Relapse following partial treatment & 0 & $(0.0)$ & 54 & (1.0) & \\
\hline Unknown/not stated & 0 & $(0.0)$ & 38 & $(0.7)$ & 0.018 \\
\hline
\end{tabular}

Key: Data are presented as no. (\%) unless otherwise indicated. IQR: interquartile range. Multidrug resistant tuberculosis (MDR TB): defined as resistant to at least isoniazid and rifampicin. NC $=$ not calculated. ${ }^{1}$ Restricted to cases with pulmonary or pulmonary plus other sites: Prison $=18$ cases; general TB population $=3112$. ${ }^{2}$ Culture-confirmed cases only: Prison $=19$ cases; general TB population $=4347 .{ }^{3}$ Derived from Fisher's exact test unless otherwise stated. ${ }^{4}$ Derived from Wilcoxon/Mann-Whitney tests.

Figure 1 shows the relationship between the time of TB diagnosis and incarceration in correctional facilities. Seven people were diagnosed with TB while they were in prison and completed their treatment while incarcerated; one was diagnosed with TB and completed treatment shortly after release. One person was diagnosed with TB shortly after being released from prison.

Contact tracing was conducted for 13 prisoners with pulmonary TB (not shown). A total of 179 contacts was identified and screened, with 44 (24.6\%) diagnosed with latent TB infection and offered preventive treatment. On six occasions, screenings were done within the prison setting. Of 59 contacts screened in the correctional facilities, two contacts had latent TB infection. Both contacts had other risk factors for TB exposure, including migration from a high TB incidence country. 


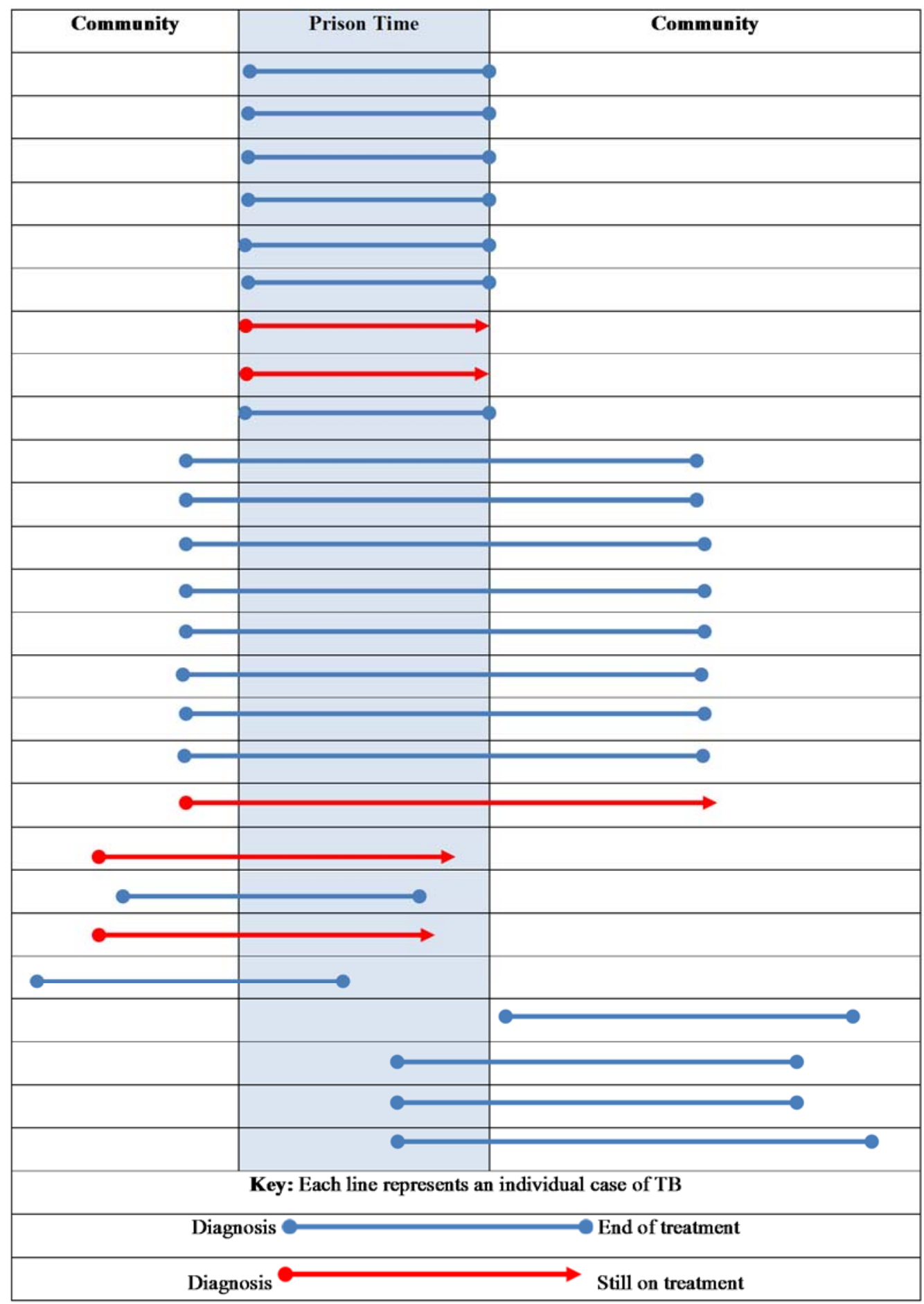

Figure 1. The relationship between incarceration in correctional facilities and tuberculosis diagnosis and treatment.

Figure 2 shows the region of birth and ages of the prisoners. Ages ranged from 16 to 71 years, and $34.6 \%$ of them were aged at least 30 years. The demographic data of the general inmates in Victorian correctional facilities (not shown) and those of the inmates who were incarcerated in correctional facilities at the time they were receiving treatment for TB over the same study period were compared. There was a significant difference in age group proportions between the two groups. The majority of the inmates who were incarcerated in correctional facilities at the time they were receiving treatment for TB were aged below 30 years $(65.4 \%)$, while the majority of the general inmates in Victorian 
correctional facilities were aged at least 30 years old (68.3\%) [12-26]. More than half $(61.5 \% ; p \leq 0.0001)$ of inmates who were incarcerated in correctional facilities at the time they were receiving treatment for $\mathrm{TB}$ were born in African countries, while in the general prison population, there were fewer inmates born in African countries $(0.8 \% ; p \leq 0.0001)$ over the same study period [11-25].

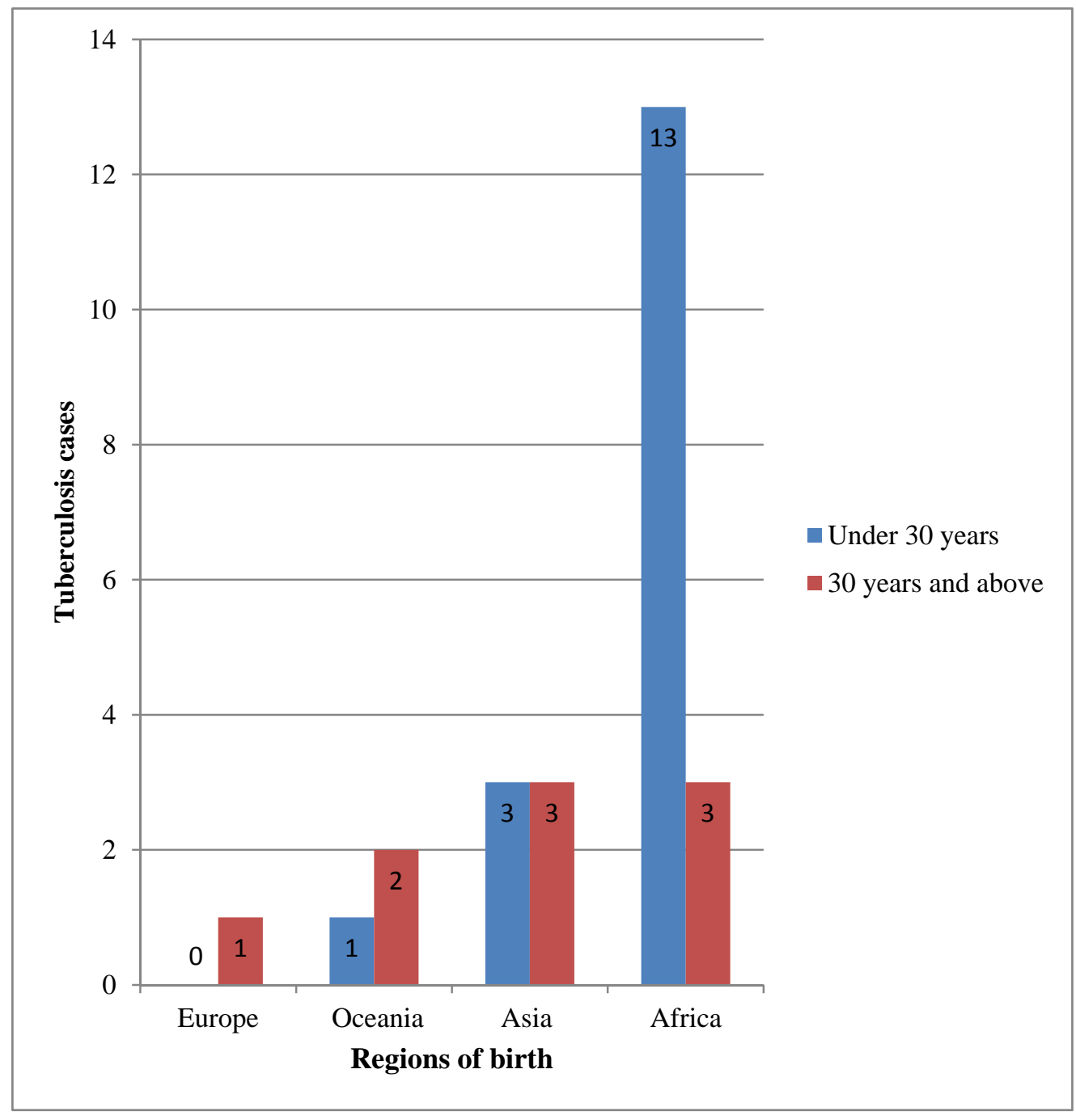

Figure 2. Regions of birth and ages.

The majority of individuals with TB were born in countries other than Australia, regardless of incarceration history. Of 22 prisoners with available information, $4(18.2 \%)$ had arrived in Australia less than 5 years prior to TB diagnosis, while 13 (59.1\%) arrived more than 10 years before diagnosis.

Table 2 compares the treatment outcomes between the general TB population and those who were incarcerated in correctional facilities at the time they were receiving treatment for TB. Of cases with assessable outcomes, there was no significant difference in treatment success between the general TB population (95.9\% (95\% CI 95.3-96.5) and those who had a history of incarceration during their treatment $(91.3 \%$ (95\% CI 70.4-97.9)) ( $p=0.105)$. Median treatment duration did not significantly differ between prisoners and the general TB population ( 274 versus 214 days, respectively; $p=0.12$ ). There were 52 deaths caused by TB and 64 cases lost to follow-up among the general TB population and none among those who were incarcerated in correctional facilities at the time they were receiving treatment for TB. 
Table 2. Treatment outcome.

\begin{tabular}{|c|c|c|c|c|c|c|c|}
\hline \multirow[t]{2}{*}{ Treatment Outcome/Assessable Outcomes } & \multirow[t]{2}{*}{ Total } & \multicolumn{3}{|c|}{$\begin{array}{l}\text { TB Cases with Prison } \\
\text { History during Treatment }\end{array}$} & \multicolumn{3}{|c|}{ General TB Population } \\
\hline & & $n$ & $\%$ & $(95 \% \mathrm{CI})$ & $n$ & $\%$ & $(95 \% \mathrm{CI})$ \\
\hline Treatment success (completed treatment or cured) & 4839 & 21 & 91.3 & $(70.4-97.9)$ & 4818 & 95.9 & $(95.3-96.5)$ \\
\hline Interrupted treatment & 27 & 1 & 4.4 & $(0.6-26.1)$ & 26 & 0.5 & $(0.4-0.8)$ \\
\hline Defaulted & 63 & 1 & 4.4 & $(0.6-26.1)$ & 62 & 1.2 & $(1.0-1.6)$ \\
\hline Died of tuberculosis & 52 & 0 & 0.0 & & 52 & 1.0 & $(0.8-1.4)$ \\
\hline Failure & 0 & 0 & 0.0 & & 0 & 0.0 & \\
\hline Lost to follow-up, outcome unknown & 64 & 0 & 0.0 & & 64 & 1.3 & $(1.0-1.6)$ \\
\hline Total assessable & 5045 & 23 & 100.0 & & 5022 & 100 & \\
\hline \multicolumn{8}{|l|}{ Non-accessible outcomes } \\
\hline Transferred out of Australia & 228 & 0 & 0.0 & & 228 & 38.2 & $(34.4-42.2)$ \\
\hline Died of other causes & 178 & 0 & 0.0 & & 178 & 29.8 & $(26.3-33.6)$ \\
\hline Still under treatment & 194 & 3 & 1.0 & & 191 & 32.0 & $(28.4-35.9)$ \\
\hline
\end{tabular}

Definitions: Cured is defined as the bacteriologically-confirmed sputum smear and positive culture at the start of treatment and negative culture in the final month of treatment and on at least one previous occasion. Interrupted treatment is defined as treatment interrupted for two months or more but completed. Defaulted is defined as the failure to complete treatment. Failure is defined as culture-positive sputum at five months or later.

\section{Discussion}

Overall, we found that there is a low prevalence of TB in Victorian prisoners, and little evidence that incarceration in this context is a significant risk factor for TB disease.

While we found that treatment outcomes were similar, there are significant differences in approaches to TB management between prisoners and the general population in our setting. Most TB therapy in Victoria is provided by supported patient self-administration and involves the Victorian Tuberculosis Program nurses monitoring patients during home visits, telephone calls, and clinic attendances; directly observed therapy (DOT) is reserved for identified at-risk patients and is used in approximately $1 \%$ of cases [27]. Tuberculosis treatment in correctional facilities was provided by DOT, in keeping with medication policies for all therapy in this setting. For continuity of care, all cases that had a history of being incarcerated continued to receive DOT following release from prison. Transitions between models of care may present a range of challenges for individuals with $\mathrm{TB}$, and our review found that a majority of this cohort entered and/or left prison during their period of treatment. Considered efforts are required to harmonise management and communication when transfers occur between jurisdictions or care providers, and ongoing review of policy and practice in this area will be valuable for individual patients.

Although treatment outcomes appear similar between inmates and the general population, measures of TB severity (cavitation and smear positivity) are different. This study did not explore the reasons for the differences in measures of $\mathrm{TB}$ severity between prisoners and the general population; therefore, further studies are recommended.

Our study was limited by its retrospective nature and relatively small number of cases within prison contexts. The method of identification of cases (keyword search in medical records) may have missed cases.

Our review focused on TB notifications in relation to prison in Victoria, and did not include testing for latent TB infection (LTBI). Data from previous Australian studies [6] has suggested that prevalence of LTBI may be higher in the prison cohort than in the general community, but has not identified attributable risk to the prison environment itself [8]. While prison may not be an independent risk factor for TB infection in our context, incarcerated individuals may still be at significant risk due to other risk factors. Prisons have been used as successful opportunities to optimise health in relation to other diseases, including hepatitis $\mathrm{C}$ and human immunodeficiency virus (HIV) and strategies to identify and treat LTBI in people while in prison may assist in individual health promotion. 


\section{Conclusions}

There is low incidence of TB in Victorian prisoners, and this population does not contribute significantly to overall TB incidence. Incarceration does not appear to be a significant barrier to TB elimination in the Victorian setting; however, ongoing efforts to maintain TB control in at-risk populations are required. Opportunities to identify and treat LTBI in prison contexts may be valuable for future consideration and individual health promotion efforts.

Author Contributions: N.M. conceived the study, developed the analysis approach, performed the analysis, and drafted the manuscript. E.L.T. retrieved the data from the broader database, helped with data analysis, and supervised the study. J.D. supervised the study.

Funding: This research received no external funding.

Conflicts of Interest: The authors declare no conflict of interest.

\section{References}

1. Bone, A.; Aerts, A.; Grzemska, M.; Kimerling, M.; Kluge, H.; Michael, L.; Françoise, P.; Mario, R.; Francis, V. Tuberculosis Control in Prisons: A Manual for Programme Managers; World Health Organization: Geneva, Switzerland, 2000.

2. Centres for Disease Control and Prevention. Prevention and Control of Tuberculosis in Correctional and Detention Facilities: Recommendations from CDC; Centres for Disease Control and Prevention: Atlanta, GA, USA, 2006.

3. Macneil, J.R.; Lobato, M.N.; Moore, M. An Unanswered health disparity: Tuberculosis among correctional inmates, 1993 through 2003. Am. J. Public Health 2005, 95, 1800-1805. [CrossRef] [PubMed]

4. Baussano, I.; Williams, B.G.; Nunn, P.; Beggiato, M.; Fedeli, U.; Scano, F. Tuberculosis incidence in prisons: A systematic review. PLoS Med. 2010, 7, 1470. [CrossRef] [PubMed]

5. Lambert, L.A.; Armstrong, L.R.; Lobato, M.N.; Ho, C.; France, A.M.; Haddad, M.B. Tuberculosis in jails and prisons: United States, 2002-2013. Am. J. Public Health 2016, 106, 2231-2237. [CrossRef] [PubMed]

6. McDaniel, C.J.; Chitnis, A.S.; Barry, P.M.; Shah, N. Tuberculosis trends in California correctional facilities, 1993-2013. Int. J. Tuberc. Lung Dis. 2017, 21, 922-929. [CrossRef] [PubMed]

7. Butler, T.; Levy, M. Mantoux positivity among prison inmates-New South Wales, 1996. Aust. N. Z. J. Public Health 1999, 23, 185-188. [CrossRef] [PubMed]

8. Levy, M.H.; Butler, T.G.; Zhou, J. Prevalence of Mantoux positivity and annual risk of infection for tuberculosis in New South Wales Prisoners, 1996 and 2001. N. S. W. Public Health Bull. 2007, 18, 119-124. [CrossRef] [PubMed]

9. Department of Health \& Human Services, State Government of Victoria, Australia. Notify a Condition Now. 2018. Available online: https://www2.health.vic.gov.au/public-health/infectious-diseases/notifycondition-now (accessed on 9 August 2018).

10. Dale, K.; Tay, E.; Trevan, P.; Denholm, J.T. Mortality among tuberculosis cases in Victoria, 2002-2013: Case fatality and factors associated with death. Int. J. Tuberc. Lung Dis. 2016, 20, 515-523. [CrossRef] [PubMed]

11. Australian Bureau of Statistics. 4517.0-Prisoners in Australia. 2003. Available online: http://www.abs.gov. au/AUSSTATS/abs@.nsf/DetailsPage/4517.02003?OpenDocument (accessed on 1 August 2018).

12. Australian Bureau of Statistics. 4517.0-Prisoners in Australia. 2004. Available online: http:/ / www.abs.gov. au/AUSSTATS/abs@.nsf/DetailsPage/4517.02004?OpenDocument (accessed on 1 August 2018).

13. Australian Bureau of Statistics. 4517.0-Prisoners in Australia. 2005. Available online: http://www.abs.gov. au/AUSSTATS/abs@.nsf/DetailsPage/4517.02005?OpenDocument (accessed on 1 August 2018).

14. Australian Bureau of Statistics. 4517.0-Prisoners in Australia. 2006. Available online: http:/ /www.abs.gov. au/AUSSTATS/abs@.nsf/DetailsPage/4517.02006?OpenDocument (accessed on 1 August 2018).

15. Australian Bureau of Statistics. 4517.0-Prisoners in Australia. 2007. Available online: http:/ /www.abs.gov. au/AUSSTATS/abs@.nsf/DetailsPage/4517.02007? OpenDocument (accessed on 01 August 2018).

16. Australian Bureau of Statistics. 4517.0-Prisoners in Australia. 2008. Available online: http:/ /www.abs.gov. au/AUSSTATS/abs@.nsf/DetailsPage/4517.02008?OpenDocument (accessed on 1 August 2018).

17. Australian Bureau of Statistics. 4517.0-Prisoners in Australia. 2009. Available online: http://www.abs.gov. au/AUSSTATS/abs@.nsf/DetailsPage/4517.02009?OpenDocument (accessed on 1 August 2018). 
18. Australian Bureau of Statistics. 4517.0-Prisoners in Australia. 2010. Available online: http://www.abs.gov. au/AUSSTATS/abs@.nsf/DetailsPage/4517.02010?OpenDocument (accessed on 1 August 2018).

19. Australian Bureau of Statistics. 4517.0-Prisoners in Australia. 2011. Available online: http:/ /www.abs.gov. au/AUSSTATS/abs@.nsf/DetailsPage/4517.02011?OpenDocument (accessed on 1 August 2018).

20. Australian Bureau of Statistics. 4517.0-Prisoners in Australia. 2012. Available online: http:/ /www.abs.gov. au/AUSSTATS/abs@.nsf/DetailsPage/4517.02012?OpenDocument (accessed on 1 August 2018).

21. Australian Bureau of Statistics. 4517.0-Prisoners in Australia. 2013. Available online: http:/ /www.abs.gov. au/AUSSTATS/abs@.nsf/DetailsPage/4517.02013?OpenDocument (accessed on 1 August 2018).

22. Australian Bureau of Statistics. 4517.0-Prisoners in Australia. 2014. Available online: http://www.abs.gov. au/AUSSTATS/abs@.nsf/DetailsPage/4517.02014?OpenDocument (accessed on 1 August 2018).

23. Australian Bureau of Statistics. 4517.0-Prisoners in Australia. 2015. Available online: http://www.abs.gov. au/AUSSTATS/abs@.nsf/DetailsPage/4517.02015?OpenDocument (accessed on 1 August 2018).

24. Australian Bureau of Statistics. 4517.0-Prisoners in Australia. 2016. Available online: http:/ /www.abs.gov. au/AUSSTATS/abs@.nsf/DetailsPage/4517.02016?OpenDocument (accessed on 1 August 2018).

25. Australian Bureau of Statistics. 4517.0-Prisoners in Australia. 2017. Available online: http:/ /www.abs.gov. au/AUSSTATS/abs@.nsf/DetailsPage/4517.02017?OpenDocument (accessed on 1 August 2018).

26. Department of Health \& Human Services, State Government of Victoria, Australia. Management, Control and Prevention of Tuberculosis Guidelines for Health Care Providers. 2015. Available online: https:/ / www2. health.vic.gov.au/about/publications/policiesandguidelines/tuberculosis-guidelines-2015 (accessed on 25 August 2018).

27. Dale, K.D.; Globan, M.; Tay, E.L.; Trauer, J.M.; Trevan, P.G.; Denholm, J.T. Recurrence of tuberculosis in a low-incidence setting without directly observed treatment: Victoria, Australia, 2002-2014. Int. J. Tuberc. Lung Dis. 2017, 21, 550-555. [CrossRef] [PubMed]

(C) 2018 by the authors. Licensee MDPI, Basel, Switzerland. This article is an open access article distributed under the terms and conditions of the Creative Commons Attribution (CC BY) license (http:/ / creativecommons.org/licenses/by/4.0/). 